\title{
Exploring the Gap for Effective Extension of Professional Active Life in Europe
}

\author{
Will Leonard ${ }^{1}$, Hamideh Afsarmanesh ${ }^{2}$, Simon S. Msanjila ${ }^{2}$, and Jim Playfoot ${ }^{1}$ \\ ${ }^{1}$ White loop Ltd, 54 Poland Street, London W1F 7NJ, UK \\ $\{$ will, jim\}@whiteloop.com \\ ${ }^{2}$ Informatics Institute, University of Amsterdam, Science Park 107, \\ 1098 XG, Amsterdam, The Netherlands \\ \{h.afsarmanesh,s.s.msanjila\}@uva.nl
}

\begin{abstract}
Extending Professional Active Life (ePAL [2]) of elder people in Europe is affected by a number of factors in the market and society, which have the potential to either positively and negatively influence it. Current practices indicate that the European society, while started to act on this subject, is still slow to recognize the rationale behind and importance of fully supporting the extension of active professional life of seniors. Similarly, the capacity of the service sector to fully support the involvement of seniors in economical activities is at present limited, given the huge number of these seniors in different countries who need to be mobilized. This paper seeks to highlight the identified gaps related to effective mechanisms by which Europe can support its willing senior professionals to remain active. The study on gap identification addresses relevant technological, social, and organizational factors and external influences which have the potential to impact successful future life of elderly population. It also presents the methodology that is applied in our study to identify and analyze the gaps between the current practices in this area, the so-called baseline [2], and the desired future for this area as inspired in the ePAL vision [1] addressed in other research.
\end{abstract}

Keywords: Gap analysis, professional active life, vision statement.

\section{Introduction}

Past research has shown that senior professionals (i.e. retired or retiring professionals according to the regulations in respective countries [2]) in Europe view their involvement in some sort of professional activities as a fundamental element of wellness and personal fulfillment [6]. Many of these seniors resent the fact that they were forced to retire at a certain age and they would rather prefer to have the choice to continue working for as long as they wish [8]. ePAL's envisioned future is of an EU (European Union) in which active senior professionals are supported in their work towards filling the emerging skill gaps in European society. This envisioned future is also dependent on governments in different EU countries having recognized the growing trend of an aging workforce and seeing the logic of creating a legal infrastructure to facilitate seniors in extending their active role in society. 
A number of studies have highlighted that regardless of the fact that younger workers will become an increasingly scarce resource, many employers in Europe still attach negative stigmas to senior workers and demonstrate a reluctance to employ or work with them [3]. Thus fundamental societal changes must take place and these changes should follow the guidelines provided by a well-conceived vision for the desired future in this area. At the same time, supporting ICT technology-based tools need to be developed in a senior-friendly manner, which means developing tools that adapt to their needs. Therefore, the creation of new IT tools and systems are required for professionals, having the particular needs of seniors in mind [5]. Currently, there are also concerns that the needed technological, social and organizational changes, necessary to support the ePAL vision, will not take place before the problem of an aging Europe becomes even more critical.

It is therefore essential to analyze the advances in technological and organizational models in relation to their market potential and social function, in supporting the involvement of seniors in daily economic activities. In this sense, those who build these supporting tools must be aware of a growing silver economy, involving seniors and their support organizations as their principal consumers.

The research presented in this paper looks to create a critical analysis of the "gap" between the baseline and the desired vision of the ePAL. In so doing, it is intended to provide guidelines for experts, observing how difficult or easy it is to achieve every facet of the ePAL vision. Within the analysis presented in this paper, first positive and negative factors affecting the global ePAL vision are identified, and then categorized as strengths, weaknesses (the capabilities within the EU), opportunities, and threats (those influences not directly controlled by the EU).

\section{Baseline on Active Senior Professionals in EU}

Challenges related to the ageing population of the EU have been well studied by various researchers focusing on different aspects regarding senior professionals [4]. In order to support senior professionals in counteracting these challenges through continuing their active role in the socio-economic system of the EU, a coordinated vision of a positive support environment is needed. A growing awareness of challenges means that this process has already begun so it is necessary to understand the difference between where we are now and where we want to be.

In the private sector, much of these limitations are the consequence of a lack of awareness of senior professionals as potential clients. Though there are some notable exceptions, groups such as Age Concern (http://www.ageconcern.org.uk/) have highlighted the negative connotations and image which still exists concerning the older worker. Employment agencies are aware that employers have this negative image of seniors and therefore focus on jobseekers of a younger age even though they have less experience. There are also issues around quantifying the skills and experience which seniors offer, when they look to effect a career change in later life.

In the current associations of senior professionals, the scale of operations is limited. The low level of membership for these associations in the EU in relation to the percentage of elder people in Europe indicates that these associations are not well equipped to attract all potential members. The social capital and capacity of such 
associations need to be enhanced to attract more seniors. For example, the Confederation of European Senior Expert Services (CESES -www.ceses.org) represents 25 associations of senior professionals from the member states of the European Union but only offers the skills and life-time experience of around 24,000 Senior Experts. The CESES, which is the main coordinating body in the Europe, sees its role as: "to contribute to raising standards of living in developing economies through voluntary assistance to small and medium-size, financially weak, enterprises and institutions" (www.ceses.org). This though admirable aim, represents a brain drain of the skills of senior professionals working outside of Europe. However, it was observed that there is a lack of demand for services provided by senior professionals. In other words, senior professionals would have a much wider potential than the limited number of opportunities they are involved in today. Thus, there is a clear need for an improved brokerage function to identify the market needs and match them with the skills base available in these associations.

We define the "ePAL gap" as the differences which emerge between the current practice in the area and a desired future support environment for senior professionals, achieving the aims of the ePAL vision. The ePAL gap addresses and covers the three perspectives of social, organizational, and technological. The Social Perspective analyses the wider EU's recognition of the rationale behind fully supporting the extension of active professional life. The capacity of the service sector to fully support these activities and the provision of a regulatory and fiscal policy environment which can complement and support this sector is considered within the Organizational Perspective. The development of adequate ICT support by which the specific needs of senior professionals constitute part of their design process is considered and addressed in the Technological Perspective. Table below presents a summary of the baseline findings for the three perspectives.

\begin{tabular}{|l|l|}
\hline & $\begin{array}{l}\text { In the technological sector, it is clear that many of the present advances in ICT are not aimed at } \\
\text { Senior Professionals as a target user [5]. This is perhaps because those that design the software } \\
\text { by and large do not come from a senior generation and do not have a proper understanding of the } \\
\text { needs of seniors which they can input into their design. This leads to a vicious circle whereby } \\
\text { software and applications are designed for a younger user who then becomes its chief consumers } \\
\text { and market, influencing its future development. Even if this trend cannot be broken, fully } \\
\text { adaptable interfaces can help seniors overcome this lack of understanding through allowing them } \\
\text { to adapt ICT tools to their needs. }\end{array}$ \\
\hline $\begin{array}{l}\text { The above trend is no more evident than in social networks which are phenomena amongst } \\
\text { younger generations, who connect with them in vast numbers and are designed and built around } \\
\text { applications with this sector of society very much in mind. Facebook, Bebo and Youtube have } \\
\text { made ICT a very important force in mobilizing the social capital of a younger generation, who } \\
\text { both relate to this field of communication and are savvy enough to adapt it to their own user } \\
\text { generated content. Networks and interconnections are continuously expanded and enriched by } \\
\text { this new content. Since this environment is very much designed with the younger user in mind, } \\
\text { seniors are wary of and feel excluded from its use. These networks provide a level of adaptabil- } \\
\text { ity which is aimed largely at a younger generation and while successful, do not help develop } \\
\text { online cultures among seniors. }\end{array}$ \\
\hline $\begin{array}{l}\text { From an organizational perspective there is a chronic shortage of models which can effectively } \\
\text { leverage the usage of the skills of seniors. At present there is still a lack of communication } \\
\text { between employers/customers and seniors concerning the skills and experience they can } \\
\text { effectively bring to the marketplace. While some positive examples illustrate how SMEs and } \\
\text { start-ups can benefit from support offered by seniors, the demand has remained quite residual. } \\
\text { Effective new brokers are needed to ensure that such issues do not slow down the rate of } \\
\text { adaptation of recruitment and employment practices to the new demographic realities of the EU. }\end{array}$ \\
\hline
\end{tabular}




\section{Methodology for Gap Analysis in ePAL}

The purpose of the gap analysis is to identify the gap between the current baseline and the desired vision. Putting the baseline and the vision statement side by side will allow making both a conceptual as well as a "visual" comparison and therefore better identification and characterization of the gap. For this purpose the following 3 steps are adopted and applied in this paper:

Step 0: Synthesis of the baseline's findings: This step focuses on elaborating a synthesis of the findings regarding the baseline and follow up activities that are currently conducted in other studies [2], and based on the 3 perspectives of technological, organizational and social, addressed by the vision of desired future for this area addressed in other research [1], as intended to be exemplified in Fig. 1. An "aspect" in the baseline is one component of the "universe of analysis". For instance, in the technological perspective we could have an aspect referring to architectures for collaborative networks $(\mathrm{CN})$. A "desired facet" in the vision usually corresponds to an aspect, characterized with certain aimed value, to support the vision. For instance, a desired facet for the technological vision instantiation, associated to the above facet may refer to novel architectures for CNs.
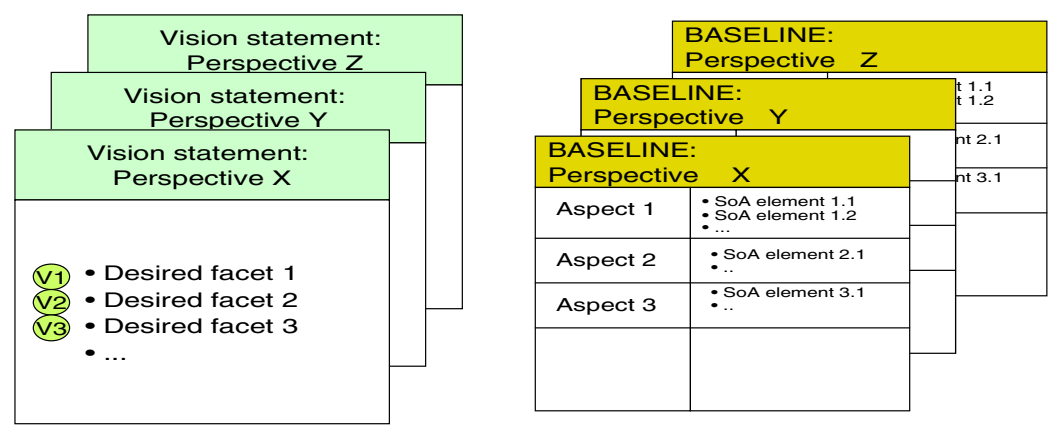

Fig. 1. Synthesis of baseline

Step 1: Elaboration of a macro-gap analysis: In this step a macroscopic analysis is elaborated regarding the global vision statement. For this purpose a SWOT (Strengths, Weaknesses, Opportunities and Threats) analysis method is used as shown in Fig. 2.

The "internal context" shall be the European Union which covers the identification of the Strengths and Weaknesses at the European level regarding the potential to

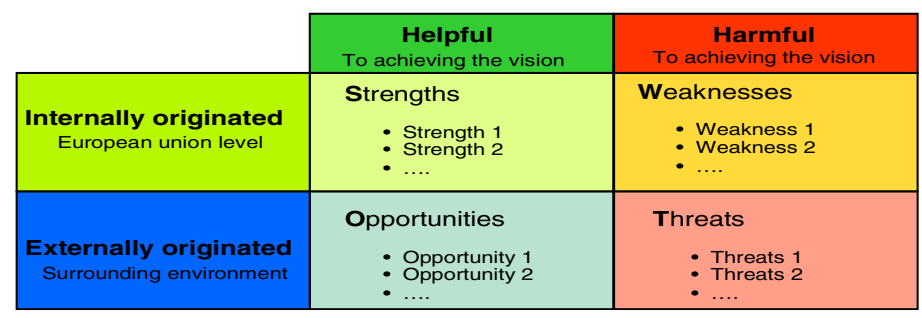

Fig. 2. SWOT analysis 
achieve the vision. The "surrounding environment" refers to both the European socioeconomic context and the regions outside Europe. It is split between opportunities that can be exploited and threats to the main actors of the ePAL Vision.

Step 2: Elaboration of a detailed gap analysis: At this stage a detailed gap analysis is performed considering the three perspectives under which the vision shall be instantiated. This step focuses on two lines of analysis: Strengths and Weaknesses / Limitations as shown in Fig. 3 to identify the relevant elements facilitating or constraining the elaboration of a plan of actions related to the vision.
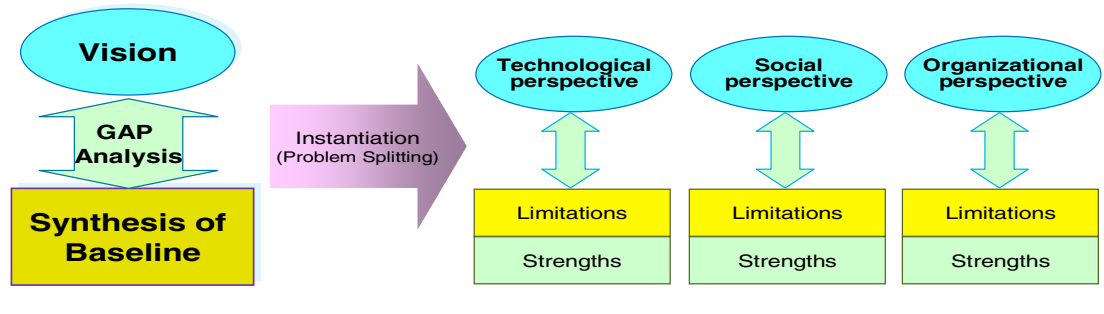

Fig. 3. Gap analysis

For this analysis, the detailed facets considered under each perspective shall define the granularity of the analysis. To determine the gaps, the desired facets in the vision statement are compared with the state of the art elements in the corresponding aspects of the baseline (Fig. 4).

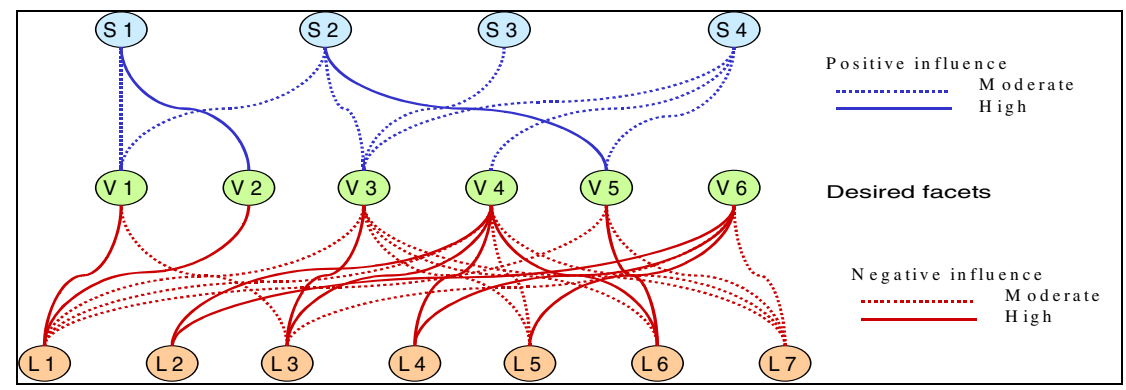

Fig. 4. Influence map - another representation

The identified gaps can be expressed through the generation of a set of three "Influence maps" to represent both the positive and negative influences of the baseline on the achievement of the vision. As shown in Fig. 4, the influence maps developed for the three perspectives provide qualitative analysis of the state of potentials and barriers on the road to reach the vision.

\section{Macro Gap Analysis for ePAL Environment}

The vision statement introduced in [1], provides a clear direction where the European society shall strive to follow, in order to achieve a balanced life for senior professionals who either need or desire to remain active in the society/market (Fig. 5). 


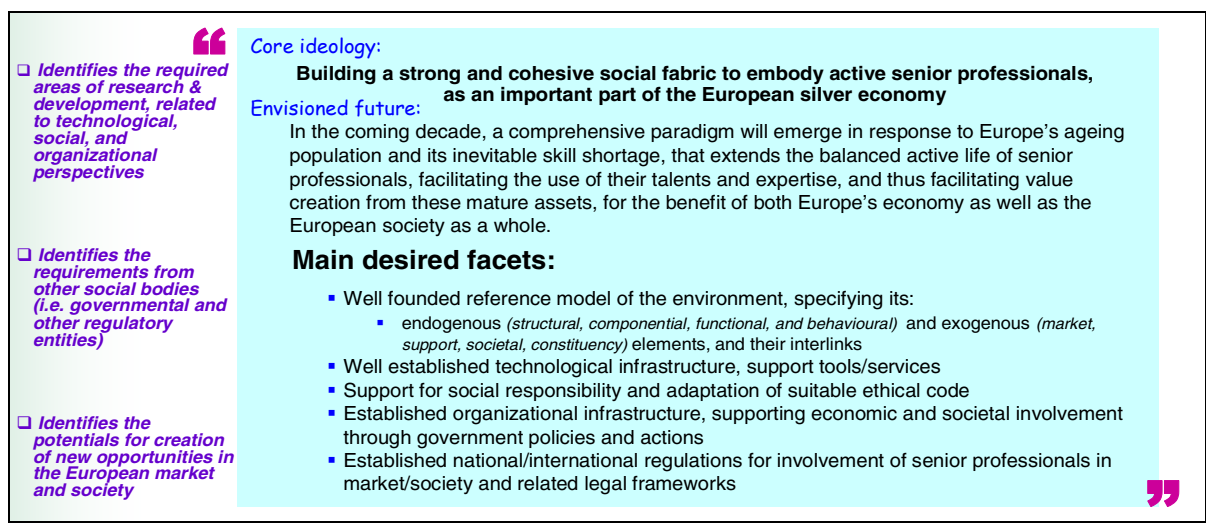

Fig. 5. $1^{\text {st }}$ vision statement for ePAL in European society [1]

The vision addresses providing opportunities and support for those seniors who are willing to get involved in socio-economic activities. It suggests the main areas needing attention from other social bodies and responsible organs, in order to reach this desired state. Clearly enough, the creation of a desired vision for ePAL for the coming decade is not a one shot action rather it is a live and interactive process.

Based on the vision statement and its respective facets as well as the baseline findings, an examination of the strengths, weaknesses, opportunities and threats was performed by applying a SWOT analysis to the ePAL environment in European society. Below are some example results of the SWOT analysis. More detailed results are presented in the project website at www.epal.eu.com.

\section{Strengths}

1. Motivation and awareness of seniors. Seniors across Europe want to work, have the desire to continue engaging in meaningful activity and are increasingly aware of their political power and economic potential.

2. Promotion of initiatives, laws and policies across Europe that support active ageing. There are many initiatives, both at EU level and at national level, that are aimed at addressing issues around seniors continued active participation in society. These include issues around employment policies, pensions, and support for lifelong learning.

3. ICT infrastructures exist across Europe to provide the technology building blocks that will be needed to implement the ePAL vision. The strength of the ICT infrastructure facilitates interaction across geographical boundaries, and provides the basis for achieving the PAL vision. The infrastructure is inducing high levels of engagement in tools that facilitate communication, collaboration, content creation and management, document management etc.

\section{Weaknesses}

1. Lack of effective role for governmental bodies within the EU. There is a lack of funding opportunities for the activities of senior professionals. More government regulations are also needed for Associations of Senior Professionals e.g. labor systems, IPR, liability. At present, there is also too much regulation in terms of the presently overly restrictive retirement laws imposed by many EU governments.

2. Weaknesses of Associations of Senior Professionals. At present there is a lack of new organizational, operational and business models for these associations. Many associations display a low level of marketing ability evidenced by their low membership rate. Another common flaw among many such associations is a lack of sufficient mechanisms for identifying funding opportunities within the EU. 
3. Lack of Support Services for Senior Professionals. There is, in comparison with other sectors of society, a low level of social networking and trust building among senior professionals. Seniors also need an educational sector which offer more options for higher and further education training opportunities. This should be coupled with more research into the job market opportunities for senior professionals.

\section{Opportunities}

1. People are becoming more community minded thanks to the web. Recent years have seen the emergence of new organizational forms and ways to work together on the web e.g. Virtual Communities and Virtual Organizations. This means trust creation is becoming easier to achieve, thanks to the use of the web in the sense that people are getting more used to trusting others remotely. These new avenues create more opportunities to cement trust amongst seniors and enable them to collaborate better.

2. The increasing scarcity of younger workers. The EU has an aging population which will mean the emergence of skill shortages and lead to a scarcity of younger workers. Thus employers will increasingly need to employ seniors to plug the skill gaps and occupy the positions that the lower number of younger workers will not be able to fill.

3. Improvements in modern medical science. People are living longer and modern medical support and healthcare provision means seniors professionals are able to remain actively involved in the socio-economic system of the EU for longer.

\section{Threats}

1. Society does not react to change. Major stakeholders in society - unions, media, politicians, businesses - fail to reach social consensus that leads to a timely restructuring of society in order to effectively accommodate the new realities of an older population.

2. Slow pace of adaptation. The pace of adaptation in society in terms of technology, business models, ways of working etc - leads to higher levels of exclusion amongst older people.

3. New technology brings privacy/ethical issues. The development of specialized technologies to facilitate human capabilities and emotional interaction increases the risk of intrusions of privacy and complications around ethical issues.

\section{Map of Influence Analysis}

In the map of influence analysis, the positive and negative factors established in the macro analysis are further detailed according to level of direct influence upon the individual facets of the ePAL Vision. In so doing, these factors have been divided amongst the three main perspectives for the vision of social, organizational and technological which help to define the extent of the challenge involved in achieving each facet of the vision as well as isolating areas of particular concern. Below we present maps of influences for some example strengths and weaknesses.

\section{Map of influence for social perspective}

\section{Strengths}

S1 The increasing scarcity of younger workers, leading companies to start changing their view of older workers

S2 Improvements in modern medical science, increasing the duration of healthy senior life

S3 Increased competitiveness in the EU Marketplace as a result of globalization, which may open new opportunities for highly experienced professionals

S4 Cross Cultural Understanding in Business means improved collaboration

\section{Limitations}

L1 Negative and outdated assumptions regarding the abilities of senior professionals persist

L2 There is still evidence of discrimination against seniors in the workplace

L3 Lack of understanding of the specific needs of senior professionals

L4 Education in the EU lacks flexibility, with more emphasis needed on life-long learning and retraining opportunities for seniors 
As shown in Table 1 the identified strengths and limitations are mapped with the following vision facets related to the social perspective:

V1: New mechanisms to enhance positive understanding and perception in society regarding the value of the abilities, skills and experience of senior professionals in the economy

V2: Motivating mechanisms for senior professionals to join associations of seniors

V3: Mechanisms to support cross-cultural interactions among senior professionals as well as to the active labor force

V4: Mechanisms to support a balanced economic benefits sharing among the entire society including senior professionals.

Table 1. Influence map for social perspective

\begin{tabular}{|c|c|c|c|c|c|}
\hline & V1 & V2 & V3 & V4 & \\
\hline S1 & & & & & Positive Influence \\
\hline S2 & & & & & High \\
\hline S3 & & & & & Moderate \\
\hline S4 & & & & & \\
\hline & & & & & Negative Influence \\
\hline L1 & & & & & High \\
\hline L2 & & & & & Moderate \\
\hline L3 & & & & & \\
\hline L4 & & & & & \\
\hline
\end{tabular}

\section{Map of influence for organizational perspective}

\section{Strengths}

S1 Some organizational approaches have manifested in practice, focused on the use of the experience and knowledge of senior professionals.

S2 Changes have emerged in ways of working, such as freelancing and service based contracts, which are more suitable for senior professionals.

S3 There are some new initiatives, laws and policies across Europe oriented towards supporting active ageing for senior professionals.

S4 New conceptual frameworks and organizational forms, e.g. the collaborative networks paradigm, as well as the implementation of pilot cases, demonstrate new ways of supporting seniors to remain active.

\section{Limitations}

L1 Lack of common EU-level policies among European countries and the EU itself on the enhancement of active life of senior professionals.

L2 Lack of proper organizational/operational models to support the establishment and management of associations of senior professionals effectively involved in socio-economic activities.

L3 Lack of committed organizations and their related business models to act as brokers for senior professionals and to build trust between senior professionals and their potential clients.

L4 Lack of comprehensive policies, regulations, and laws which favor the involvement of senior professionals in the silver economy, in particular, related to formal positions, payments, and access to opportunities.

As shown in Table 2, the identified strengths and limitations are mapped with the following vision facets relayed to the organizational perspective:

V1: Employment and retirement policies will change to provide greater flexibility for seniors as economic actors

V2: Global regulations and policies will change to encourage the participation of businesses in collaboration with senior professionals

V3: The knowledge and skills of seniors will be harnessed to generate wealth and stimulate innovation amongst European businesses

V4: New forms of intermediate organization will provide highly efficient brokerage that will help seniors engage with businesses in Europe. 
Table 2. Influence map for organizational perspective

\begin{tabular}{|r|l|l|l|l|l|l|l|}
\hline S1 & V1 & V2 & V3 & V4 & & \multicolumn{2}{|c|}{} \\
\hline S2 & & & & & & Positive Influence \\
\hline S3 & & & & & & & High \\
\hline S4 & & & & & & & \\
\hline L1 & & & & & & & \\
\hline L2 & & & & & & \multicolumn{2}{|c|}{ Negative Influence } \\
\hline L3 & & & & & & & High \\
\hline L4 & & & & & & & Moderate \\
\hline
\end{tabular}

\section{Map of influence for technological perspective}

\section{Strengths}

S1 Good progress in conceptual models for collaborative networks (although mostly focused on industry)

S2 There is already an understanding of the needed management functionalities for $\mathrm{VO}$ breeding environments / professional virtual communities

S3 Various partial models and advanced prototypes (e.g. negotiation, trust, value systems) have been developed to support collaborative environments

S4 ICT infrastructures exist across Europe to provide the communication building blocks that is needed to implement the ePAL vision

\section{Limitations}

L1 Lack of consolidated theoretical base in areas such as reference modeling for active ageing support systems

L2 Lack of effective and integrated ICT support for collaboration (till large fragmentation of functionalities)

L3 ICT research in this area too much focused on the "last phases of life", reducing the needed attention to active ageing support

L4 Fast proliferation of new tools and functionalities without a holistic approach, an obstacle for adoption by seniors

As shown in Table 3, the identified strengths and limitations are mapped with the following vision facets related to the technological perspective:

V1 Advanced collaboration support services, including teams' formation and management

V2 Development of collaboration ontology supporting variety of stakeholders

V3 Support for user-generated knowledge content

V4 "Configure yourself" based philosophy infrastructure.

Table 3. Influence map for technological perspective

\begin{tabular}{|c|c|c|c|c|c|c|c|}
\hline & V1 & V2 & V3 & V4 & & & \\
\hline S1 & & & & & & & \\
\hline S2 & & & & & & Positive Influence \\
\hline S3 & & & & & & & Moderate \\
\hline S4 & & & & & & & \\
\hline & & & & & & & \\
\hline L1 & & & & & Negative Influence \\
\hline L2 & & & & & & & High \\
\hline L3 & & & & & & & \multicolumn{2}{c|}{ Moderate } \\
\hline
\end{tabular}

\section{Summaries of Gap Analysis Findings}

Social perspective: The social perspective of the ePAL vision is perhaps the most difficult to achieve as it requires a mass mobilization of a large number of actors. Social cohesion and a change in attitudes towards older professionals is a difficult task. The traditional view that those reaching retirement age are about to make the transition to passive actors must become largely redundant due to the pan European 
demographic changes of an aging EU. The recognition of this new role is vital for EU governments and older workers themselves. Social cohesion is an important area of consideration as the rise of the senior workers will not happen in isolation. As an ever increasing percentage of EU society, seniors' contribution to their society needs to grow. To ensure that the potential of this contribution is properly coordinated new mechanisms which gather consensus and outline the role of seniors in EU will need to be created. It is important that such mobilization should not lead to the ghettoisation of seniors and become a source of division within EU society.

Seniors and those just starting employment will have to learn to work together and effectively communicate. As part of this there will have to be a greater understanding of the new needs this will create and new forms of leveraging the capabilities of seniors. At the same time "seniority" (position in a company) within a business environment will no longer be so closely linked to age. Maureen Minehan, as early as 1997 noted a trend that while older workers will have to accept that pay in later life will become more linked to performance rather than "seniority", human resource departments are increasingly excepting that new forms of health and other benefits will come into place to attract senior workers [7]. Recent studies show that many older workers still consider themselves to be discriminated in the workplace and some employers are prejudiced by stigmas of inadaptability and lack of learning ability when they apply for jobs [3]. Mechanisms to support cross generational interaction between seniors and younger citizens; fomenting inter-generational solidarity and understanding within the EU would have the knock on effect of improving employment systems and creating a healthy employment balance.

Organizational perspective: The organizational perspective of ePAL can be divided into two main strands. The first is employment policies and regulations which will facilitate the rise of the active senior professional and the second is mechanisms which will harness the potential of these actors and provide increased support and structure to their contribution to the EU economy. As mentioned earlier, there is a need for a full understanding of what seniors, in a non traditional role as active professionals, can bring to society. This requires in part a mobilization of senior social capital by seniors themselves supported through relevant mechanisms.

A full understanding of the needs and issues around active senior professionals can provide the basis for strategic investment into more efficient and specific forms of brokerage and support services tailored to the realities of the silver economy. Such brokerage should also take into account ways of mitigating against problems with cross generational communication and what are the most efficient forms of work for seniors as compared to other types of professionals. It seems increasingly likely that the extension of active life will go hand in hand with a change in the average person's career trajectory. Labor systems have attracted a lot of interest and the reduced labor rigidity and indeed rights such systems bring would have a significant impact on the way people work in the future. Of most relevance to ePAL is the effect such labor law changes would have on the traditional divisions between pre and post retirement life. Fewer EU citizens are working long term for one employer and are incentivized to retrain themselves throughout their lives and consequently take more control of financial provision for their retirement. An accent on life long learning implies that many people will have to take time out of their active professional lives at several stages of their career, with retirement planning forming part of a more sophisticated concept of 
career and financial planning. Brokerage for senior professionals will need to develop a wider knowledge of how it fits into this equation. Financial services specifically aimed at seniors will have to do the same. However, a pool of senior talent which is used to remarketing itself would in theory, make the role of brokers in leveraging this talent to diverse sources easier. Such career fluidity would also have a consequential effect on the concept of a senior worker itself.

Technological perspective: There are a number of new ICT technologies and advances which show the potential to facilitate the extension of professional active life amongst seniors, but their scope at present is not clearly defined and there is a real need for their advancement to be steered towards the needs of senior professionals.

In order for advances in ICT brokerage systems to have the desired effect they should be developed with a proper understanding of the needs of those who will be using them. This may seem an obvious point, but it would appear important that the technological aspects of ePAL advance in line with organisational models. In a highly competitive industry which develops at a lightning pace with a constantly updated line of services in which new advances quickly become redundant this would mean too much of a barrier to its normal development. One solution to this problem, which is very much in line with present technological trends, is to offer a high degree of built in adaptability to new technology. Advances in "configure yourself" technology and support systems for user generated knowledge content along with easily customizable interfaces are crucial to allow brokers and senior professionals themselves to react to changes in a non static marketplace. Where seniors are working with younger professionals' adaptable technology would have to be compatible and not virtually alienate seniors from their co-workers. The issue of stigma could become a problem within the context of seniors working within a professional environment - if a senior uses an adaptive technology in order to interact with others, this may be seen as a sign of weakness to effectively do the job.

The introduction of new working patterns, relying for instance on remote collaboration of teams of senior professionals interacting with brokerage entities and customers, also introduces the need for new infrastructure functionalities and tools supporting e.g. trust building, value systems alignment, performance assessment in collaborative environments and distributed negotiation mechanisms, etc.

\section{Conclusion}

The conclusion to be drawn from the results of the performed gap analysis study is that in parallel with the needed development of new supporting technologies, there is a need for a change in culture and attitudes towards older workers. This cultural change is something which must pervade both the public and private sector. From a public sector point of view this problem manifests itself in such things as policies which consider the $+55 \mathrm{~s}$ as a homogeneous group and see healthcare technologies as serving the same group of citizens as leveraging the skills of senior workers. In the private sector, there seems to be a set of persisting overarching negative assumptions about a very diverse sector of society. Furthermore, there is a real lack of recognition of senior professionals as a potential customer base for new ICT tools, which is needed to drive forward change and development of network technologies as well as 
support systems for an increasingly growing but unexploited marketplace, one which is vital for the economic and social prosperity of the EU. It is arguable that were these cultural changes to take place and a greater appreciation of the active senior professional to emerge, there would be a knock on effect in terms of organizational and technological development. An increased demand for active senior professionals would create new markets for improved support infrastructures. Equally, the creation of organizational models which make the leveraging of professional senior talent efficiently available would serve to counteract negative preconceptions of older workers and in turn increase demand for their services.

One of the key purposes of the gap analysis presented in this paper is to highlight areas of difficulty within the ePAL vision. Difficulties in the context of the vision do not reflect upon the validity or value of the various facets presented, but rather how realistic they would be to achieve or pointing to how much effort they would require given the current political and socio-economic situation in the EU and beyond.

Acknowledgement. This work was supported in part by the ePAL project funded by the European Commission. The authors thank for contributions from partners in the ePAL consortium.

\section{References}

1. Afsarmanesh, H., Camarinha-Matos, L.M., Msanjila, S.: A well-conceived vision for extending professional life of seniors. In: Proceedings of PRO-VE 2009 conference (September 2009) (to appear)

2. Camarinha-Matos, L.M., Afsarmanesh, H.: The need for a strategic R\&D roadmap for active ageing. In: The proceedings of PRO-VE 2009 conf. (September 2009) (to appear)

3. Canziani, P., Petrongolo, B.: Firing costs and stigma: A theoretical analysis and evidence from microdata. European Econ. Review 45(10), 1877-1906 (2001)

4. DHSSPS: Equality and Inequalities in Health and Social Care: A Statistical Overview, Inequalities and Unfair Access Issues Emerging from the DHSSPS (2004)

5. Hernandez-Encuentra, E., Pousada, M., Gomez-Zuniga, B.: ICT and Older People: Beyond Usability. In Educational Gerontology. Special issue on Adult Education and Lifelong Learning 35(3), 226-245 (2009)

6. Kang, M., Russ, R., Ryu, J.S.: Wellness for Older Adults in Daily Life. Oklahoma Cooperative Extension Fact Sheets, T-2237 (2008), http: / / osufacts .okstate. edu

7. Minehan, M.: The aging baby boomers - impact of post-retirement employment on companies HR Magazine(1997), http: / / www . hrmagazine.co.uk/

8. Munnell, A.H.: Policies to promote labor force participation of older people - working paper. Opportunities for Older Americans Series (2006) 